\title{
Balloon protection of the left subclavian artery in debranching thoracic endovascular aortic repair
}

Yoshimasa Seike, MD, ${ }^{\text {a }}$ Hitoshi Matsuda, $\mathrm{MD}, \mathrm{PhD},{ }^{a}$ Yosuke Inoue, MD, ${ }^{\mathrm{a}}$ Atsushi Omura, MD, PhD, ${ }^{\mathrm{a}}$ Kyokun Uehara, $\mathrm{MD}, \mathrm{PhD},{ }^{\mathrm{a}}$ Tetsuya Fukuda, $\mathrm{MD}, \mathrm{PhD},{ }^{\mathrm{b}}$ and Junjiro Kobayashi, $\mathrm{MD}, \mathrm{PhD}^{\mathrm{a}}$

\section{ABSTRACT}

Objectives: Since 2012, we have routinely applied balloon protection of the proximal left subclavian artery to prevent embolic events through the left vertebral artery during debranching thoracic endovascular aortic repair. This study aimed to study the effectiveness of balloon protection of the proximal left subclavian artery.

Methods: We reviewed the medical records of 157 patients who underwent debranching thoracic endovascular aortic repair between 2007 and 2017. Of these, 71 patients for whom balloon protection of the proximal left subclavian artery was used were assigned to the balloon protection of the proximal left subclavian artery group (58 men; age: $78 \pm 6.7$ years), and 86 patients were assigned to the control group (66 men; age: $78 \pm 8.9$ years). A total of 51 patients from each group were matched by their propensity scores to adjust for differences in the patients' characteristics.

Results: Perioperative stroke was significantly lower in the balloon protection of the proximal left subclavian artery group than in the control group $(0 \%$ : $0 / 71 \mathrm{vs}$ $7.9 \%: 7 / 86, P=.014)$. Freedom from all causes of mortality at 2 and 4 years was significantly higher in the balloon protection of the proximal left subclavian artery group compared with the control group $(93 \% / 76 \%$ vs $77 \% / 59 \%, P=.015)$. Freedom from aortic death at 2 and 4 years was similar in both groups $(97 \% / 97 \%$ vs $91 \% / 86 \%, P=.094)$. Propensity score matching yielded similar results of better freedom from all causes of mortality in the balloon protection of the proximal left subclavian artery group $(93 \% / 93 \%$ vs $81 \% / 63 \%, P=.017)$ and equivalent aortic death in both groups $(95 \% / 95 \%$ vs $92 \% / 88 \%, P=.30)$.

Conclusions: Debranching thoracic endovascular aortic repair using balloon protection of the proximal left subclavian artery demonstrated more appropriate early and late outcomes. Evaluation using propensity score matching enhanced the efficacy of balloon protection of the proximal left subclavian artery. ( $\mathrm{J}$ Thorac Cardiovasc Surg 2019;157:1336-45)

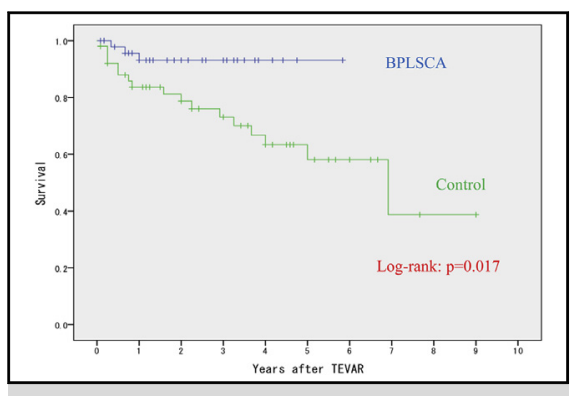

Survival in the balloon protection group was better than in the control group after matching.

\section{Central Message}

d-TEVAR using BPLSCA revealed more appropriate early and late outcomes. Evaluation using PSM enhanced the efficacy of BPLSCA.

\section{Perspective}

d-TEVAR using BPLSCA revealed more appropriate early and late outcomes. Evaluation using PSM enhanced the efficacy of BPLSCA. The comprehensive strategy to prevent stroke during d-TEVAR, including BPLSCA, has contributed to the marked reduction of stroke and mortality.

See Commentaries on pages 1346 and 1348.
Thoracic endovascular aortic repair (TEVAR) has been used for aortic arch aneurysms by using supra-aortic bypass with reportedly successful outcomes. ${ }^{1-3}$ Since 2008 , we have indicated debranching TEVAR (d-TEVAR) for

From the Departments of ${ }^{\mathrm{a} C a r d i o v a s c u l a r ~ S u r g e r y ~ a n d ~}{ }^{\mathrm{b}}$ Radiology, National Cerebral and Cardiovascular Center, Osaka, Japan.

Read at the American Association for Thoracic Surgery Aortic Symposium 2018, New York, New York, April 26-27, 2018.

Received for publication May 27, 2018; revisions received Sept 25, 2018; accepted for publication Oct 11, 2018; available ahead of print Nov 14, 2018.

Address for reprints: Hitoshi Matsuda, MD, PhD, 5-7-1 Fujishiro-dai, Suita, Osaka, Japan 565-8565 (E-mail: hitmat@mist.ocn.ne.jp).

$0022-5223 / \$ 36.00$

Copyright (c) 2018 by The American Association for Thoracic Surgery

https://doi.org/10.1016/j.jtcvs.2018.10.061 treating aortic arch aneurysms, mainly for selected elderly patients with severe comorbidities, such as chronic obstructive pulmonary disease (COPD), cardiac dysfunction, neurologic dysfunction, and malignancy. However, despite advancements in the devices and techniques, perioperative stroke remains an important complication after d-TEVAR, with prior studies reporting approximately $3.8 \%$ to $8 \%$ incidence of stroke. ${ }^{3-5}$

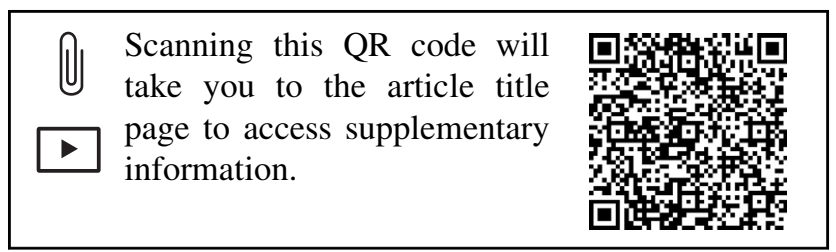




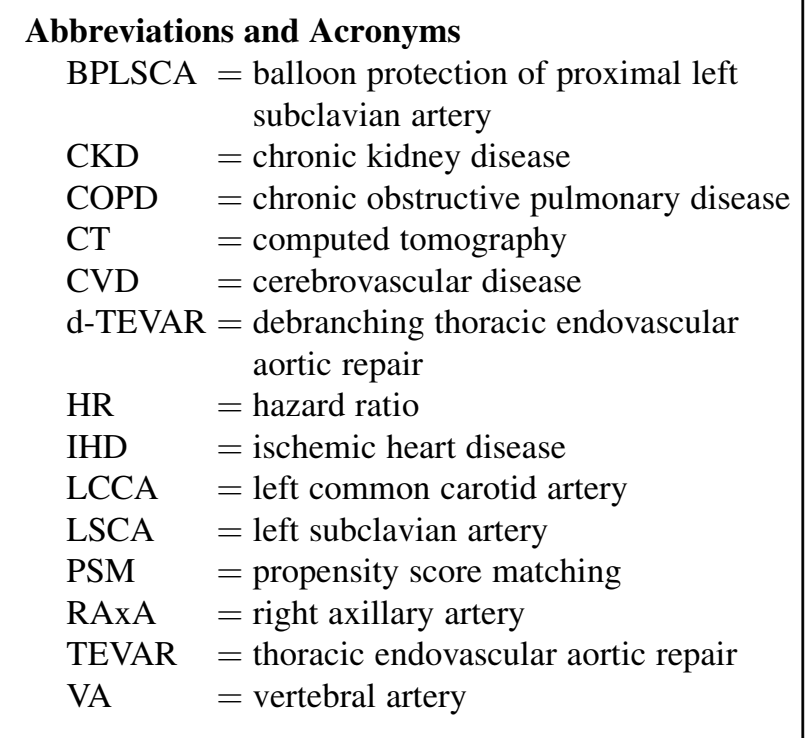

In general, preoperative contrast-enhanced computed tomography (CT) may be useful for detecting high-risk patients with "shaggy aorta." In addition, unstable or vulnerable aortic atheroma is well known as a risk factor of stroke. ${ }^{4}$ Moreover, carotid or aortic intraplaque hemorrhages on magnetic resonance imaging have revealed an association with symptomatic stroke. ${ }^{6}$ Nevertheless, the solution for preventing perioperative stroke during d-TEVAR has not been established.

In terms of the vascular distribution of stroke, some researchers concluded that stroke involving the posterior cerebral circulation was identified as the most frequent complication after TEVAR. ${ }^{4,7,8}$ Since 2012, we have routinely applied balloon protection of proximal left subclavian artery (BPLSCA) to prevent embolic events through the left vertebral artery during d-TEVAR. However, it remains unclear how BPLSCA influences the outcomes of d-TEVAR, including mortality and morbidity. The aim of the present study was to review our clinical results of d-TEVAR and to determine the effectiveness of BPLSCA in reducing chances of stroke and mortality.

\section{MATERIALS AND METHODS}

This observational retrospective study included 157 patients who underwent d-TEVAR for nondissecting aortic arch aneurysm at our institution between January 2008 and February 2017. The study exclusion criteria included Stanford type A aortic dissection. A total of 20 patients with aortic arch aneurysms showing concomitant Stanford type B aortic dissection were included in this study. Of the 157 patients included in this study, 71 for whom BPLSCA was used were assigned to the BPLSCA group (58 men; age: $78 \pm 6.7$ years), and 86 were assigned to the control group (66 men; age: $78 \pm 8.9$ years). The patient characteristics of both groups are listed in Table 1.

Preoperative cerebrovascular disease (CVD) was defined as the presence of permanent focal or global neurologic dysfunction (which preoperatively persisted) or a history of cerebrovascular events, as confirmed by CT. Ischemic heart disease (IHD) was defined as stenosis greater than $75 \%$ for at least 1 branch of the coronary arteries. COPD was defined as a forced expiratory volume less than $70 \%$ of the normal value or the daily use of a bronchodilator. Chronic kidney disease (CKD) was defined as a serum creatinine level greater than $1.5 \mathrm{mg} / \mathrm{dL}$ or a requirement for hemodialysis. Malignancy was considered for patients with a history of surgical or medical treatment for malignant tumor.

\section{Patient Characteristics}

Patients in the control group were significantly older $(P=.024)$. IHD ( $13 \%$ vs $26 \%, P=.043$ ) was more prevalent in the control group, and prior TEVAR repair $(9.9 \%$ vs $2.3 \%, P=.043)$ was more prevalent in the BPLSCA group. Other variables revealed no differences between the 2 groups (Table 1).

\section{Bypass Procedure of Debranching Thoracic Endovascular Aortic Repair}

The different technical approaches for d-TEVAR used in this study are listed in Figure E1.

Zone $0(\mathrm{n}=33)$ : The methodology of d-TEVAR with zone 0 landing has chronologically changed.

Between 2008 and $2012(n=11)$ : Through a median sternotomy, bypass from the ascending aorta to the brachiocephalic artery, left common carotid artery (LCCA), and left subclavian artery (LSCA) $(\mathrm{n}=8)$ or left axillary artery (LAxA) $(\mathrm{n}=3)$ was created, and TEVAR was performed as per the standard procedure with access from the groin.

Since $2012(\mathrm{n}=11)$ : The chimney stent-graft technique was performed with supra-aortic bypass in the same fashion as for zone 1 landing, as described next. ${ }^{9}$ A stent-graft (Excluder Iliac Extender; WL Gore \& Associates, Inc, Newark, Del) introduced into the ascending aorta from the right axillary artery (RAxA) and the main stent-graft (TAG or cTAG; WL Gore \& Associates, Inc) from the groin were simultaneously deployed.

Since $2015(\mathrm{n}=7)$ : The real chimney technique was introduced. ${ }^{10}$ This technique allows supra-aortic bypass from the ascending aorta without a side clamp. Briefly, the triple-branched graft is sheeted down on the ascending aorta with 6 mattress sutures, and the leg extension of the Excluder is inserted into the ascending aorta through the sheath inside this graft.

The other uncommon cases $(n=4)$ : Regardless of the date, exceptions included 4 cases of bypass from the ascending prosthetic graft.

Zone $1(n=73)$ : RAxA or right common carotid artery was selected as the inflow artery. A T-shaped $8 \times 8$-mm expanded polytetrafluoroethylene graft was used for the bypass from the RAxA $(n=62)$ to the LCCA and from the LAxA or right common carotid artery $(\mathrm{n}=11)$ to the LCCA and LSCA.

Zone $2(\mathrm{n}=51)$ : An 8-mm expanded polytetrafluoroethylene graft was used for the axillo-axillary bypass $(\mathrm{n}=18)$ and LCCA to LSCA bypass $(\mathrm{n}=27) ; 6$ patients had no bypass grafting.

\section{Device for Debranching Thoracic Endovascular Aortic Repair}

The Gore TAG or cTAG was used in 88 patients $(56.1 \%)$, the Valiant (Medtronic, Inc, Minneapolis, Minn) was used in 45 patients $(28.6 \%)$, the Talent (Medtronic, Inc) was used in 5 patients $(3.2 \%)$, the Zenith TX2 (Cook, Bloomington, Ind) was used in 8 patients $(5.1 \%)$, the RELAY Plus (Bolton Medical Inc, Sunrise, Fla) was used in 6 patients (3.8\%), and a Matsui-Kitamura stent (Kitamura Inc, Kanazawa, Japan) was used in 5 patients $(3.2 \%)$

The selection of a stent graft depends on factors such as periodical availability, the patient's emergency, landing zones, and the surgeon's preference. Our current primary choice according to landing zones are as follows: the cTAG with short tip and proximal uncovered portion for zone 
TABLE 1. Comparison of patients' characteristics (overall and matched cohort)

\begin{tabular}{|c|c|c|c|c|c|c|c|c|}
\hline \multirow[b]{2}{*}{ Variable } & \multicolumn{4}{|c|}{ Overall } & \multicolumn{4}{|c|}{ Matched } \\
\hline & BPLSCA: 71 & Control: 86 & $P$ value & $\overline{\text { SMD }}$ & BPLSCA: 51 & Control: 51 & $P$ value & SMD \\
\hline Median age (y) & 77 & 78 & .024 & 0.11 & 78 & 78 & .88 & 0.03 \\
\hline Male:female & $58: 13$ & $66: 20$ & .45 & 0.12 & $39: 12$ & $35: 14$ & .65 & 0.07 \\
\hline CVD & $15(21 \%)$ & $29(34 \%)$ & .08 & 0.29 & $14(28 \%)$ & $16(31 \%)$ & .66 & 0.11 \\
\hline IHD & $9(13 \%)$ & $22(26 \%)$ & .043 & 0.37 & $7(14 \%)$ & $9(17 \%)$ & .59 & 0.11 \\
\hline Low $\mathrm{EF}(<40 \%)$ & $1(1.4 \%)$ & $7(8.1 \%)$ & .056 & 0.32 & $1(2.0 \%)$ & $0(0 \%)$ & .32 & 0.20 \\
\hline COPD & $12(17 \%)$ & $17(20 \%)$ & .65 & 0.08 & $9(17 \%)$ & $9(17 \%)$ & 1.0 & $<0.001$ \\
\hline $\mathrm{CKD}(\mathrm{Cr}>1.5)$ & $4(5.6 \%)$ & $11(13 \%)$ & .54 & 0.24 & $4(7.8 \%)$ & $1(2.0 \%)$ & .17 & 0.28 \\
\hline Malignancy & $7(9.9 \%)$ & $2(2.3 \%)$ & .24 & 0.18 & $6(12 \%)$ & $3(5.9 \%)$ & .30 & 0.20 \\
\hline Emergency & $4(5.6 \%)$ & $12(14 \%)$ & .086 & 0.27 & $4(7.8 \%)$ & $2(3.9 \%)$ & .40 & 0.17 \\
\hline History of type B dissection & $13(18 \%)$ & $7(8.1 \%)$ & .057 & 0.30 & $6(12 \%)$ & $3(5.9 \%)$ & .30 & 0.20 \\
\hline Prior intervention on AAA & $4(5.6 \%)$ & $9(10 \%)$ & .27 & 0.14 & $3(5.9 \%)$ & $2(3.9 \%)$ & .65 & 0.09 \\
\hline Prior median sternotomy & $6(8.5 \%)$ & $9(10 \%)$ & .85 & 0.03 & $5(9.8 \%)$ & $5(9.8 \%)$ & 1.0 & $<0.001$ \\
\hline Prior TEVAR repair & $7(9.9 \%)$ & $2(2.3 \%)$ & .043 & 0.35 & $1(2.0 \%)$ & $2(3.9 \%)$ & .56 & 0.12 \\
\hline Proximal landing zone 0 & $11(15 \%)$ & $22(26 \%)$ & .27 & 0.25 & $10(19 \%)$ & $16(31 \%)$ & .34 & 0.35 \\
\hline zone 1 & $34(48 \%)$ & $39(45 \%)$ & - & - & $31(53 \%)$ & $28(53 \%)$ & - & - \\
\hline zone 2 & $26(37 \%)$ & $25(29 \%)$ & - & - & $14(28 \%)$ & $8(16 \%)$ & - & - \\
\hline
\end{tabular}

BPLSCA, Balloon protection of proximal left subclavian artery; SMD, standardized mean difference; $C V D$, cerebrovascular disease; $I H D$, ischemic heart disease; $E F$, ejection fraction; $C O P D$, chronic obstructive pulmonary disease; $C K D$, chronic kidney disease; $C r$, creatinine; $A A A$, abdominal aortic aneurysm; TEVAR, thoracic endovascular aortic repair.

0 landing TEVAR and the Valiant that allows stable positioning for zone 1 . However, any other endoprosthesis is also selected for these landing zones, and no specific stent graft was selected primarily for zone 2 .

\section{Methods of Balloon Protection of Proximal Left Subclavian Artery and Left Subclavian Artery Embolization}

After the bypass procedure of d-TEVAR, the left axillary artery near, usually proximal to, the anastomosis for debranching bypass was punctured with a 9F BRITE TIP sheath introducer (Cordis, Miami, Fla) directly after the purse-string suture. A 9F Optimo temporary occlusion balloon-guiding catheter (Tokai Medical Products, Aichi, Japan) was advanced with a 5F straight catheter coaxial system and placed proximal to the LSCA, usually just proximal to the orifice of the vertebral artery (Figure 1, A). After the presence of arterial occlusion was confirmed by injection of contrast through the balloon-guiding catheter, the balloon was initially inflated to arrest the antegrade flow from LSCA before initiating the catheterization to the aortic arch (Figure 1,B).

After the deployment of the endograft and TEVAR were completed, the side port of the Optimo catheter was connected to the $50-\mathrm{mL}$ syringe and aspiration was applied 2 to 3 times manually. Finally, the Optimo catheter was slowly removed, and embolization was performed using coil (before 2014) or the Amplatzer Vascular Plug II (St Jude Medical, Plymouth, Minn) through the balloon catheter lumen to the origin of LSCA (Figure 1, C) (Video 1).

In the early phase of the study period between 2007 and 2011, BPLSCA was limitedly applied in 3 of 50 patients $(6 \%)$, and a higher percentage of stroke, approximately $10 \%$, was observed. In 2012, BPLSCA was discreetly applied in approximately $20 \%$ of patients $(5 / 24)$ in whom stroke was highly expected. After the safety was confirmed, BPLSCA has been used widely in approximately $80 \%$ of patients $(65 / 80)$ since 2013.
When embolic stroke due to the thrombus inside the proximal arch was expected, other cervical branches were protected by a balloon catheter or simple clamp in 8 patients $(5.1 \%)$ in addition to BPLSCA.

\section{Analysis for End Point}

The primary outcome of this study was all-cause mortality during the follow-up period, including early death. Mortalities including perioperative stroke were compared between the BPLSCA and control groups. Perioperative stroke was defined as symptomatic stroke that occurs during an operation or until 30 days after d-TEVAR. The incidence of any type of endoleak was also compared between the 2 groups. Regarding the subgroup analysis, the aortic death rate was compared between the 2 groups. Aortic death was defined as hospital death or late death due to aortic dissection, aortic rupture, graft infection, and unknown causes. In addition, the death rate was reassessed by propensity score matching (PSM).

The preoperative values and postoperative courses were assessed using univariate and multivariate analyses to identify the risk factors for all-cause mortality and stroke during the follow-up period.

A patient in the BPLSCA group was then matched with a patient in the control group using the closest PS by caliper matching without replacement, and the maximum difference of the PS was set at less than 0.03 , it was defined by this equation: 0.20 standard deviation of logit of the PS. A total of 51 patients from each group were matched using propensity scores to adjust for differences in the patients' characteristics (Table 1). A balance check was performed after matching, and the 2 groups were relatively comparable for most confounders (standardized mean difference $<0.20$ ) excluding CKD and proximal landing zone.

\section{Data Collection and Statistical Analysis}

The data were collected from hospital admission and outpatient medical records. All patients were followed up as outpatients at our center or by a local physician. This retrospective observational study was approved by the 

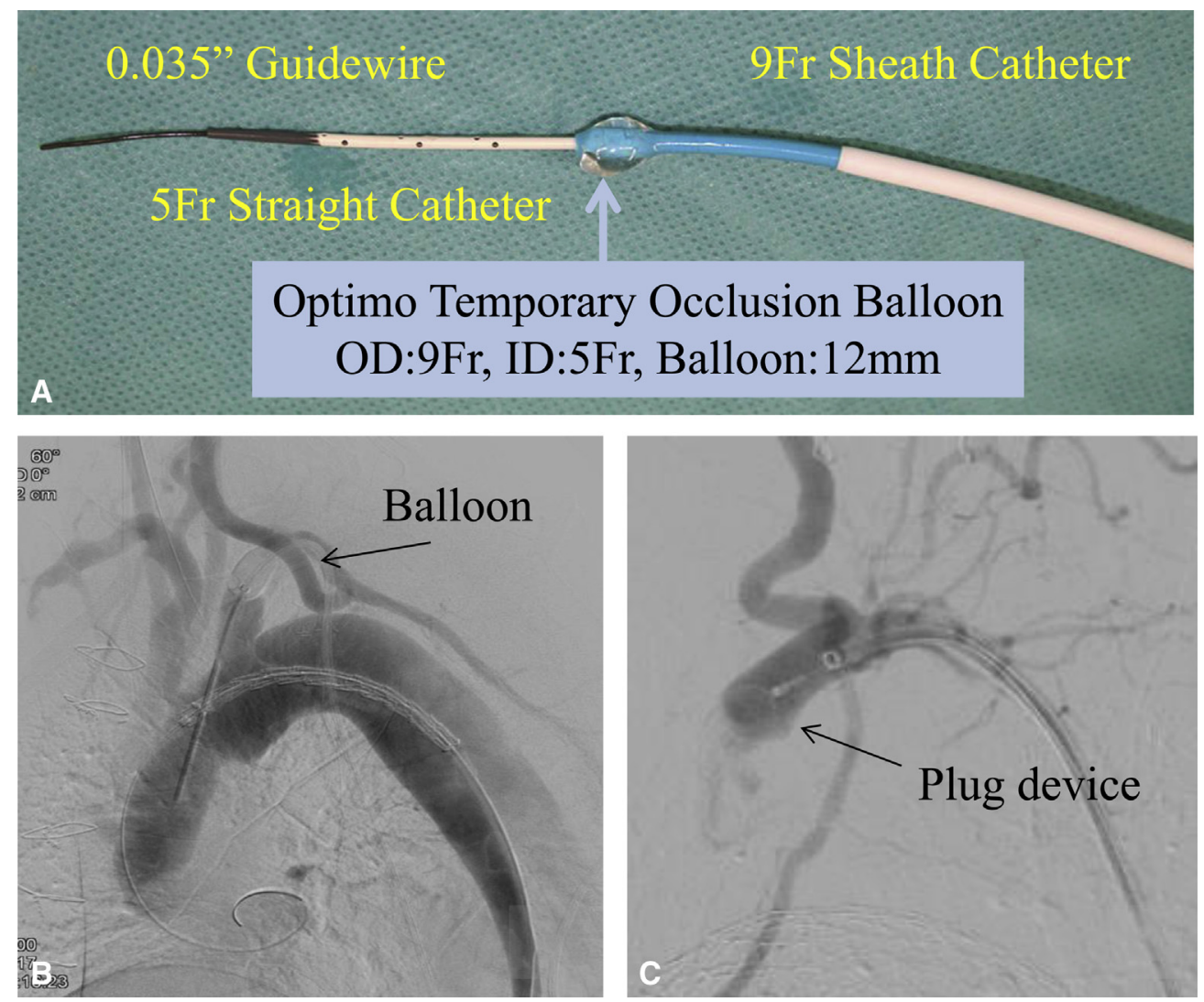

FIGURE 1. A, The system of balloon protection of proximal LSCA and LSCA embolization. In the lumen of a 9F occlusion balloon-guiding catheter, a $5 \mathrm{~F}$ straight catheter was inserted with 0.035 " guidewire inside. B, The balloon is inflated in the proximal portion of LSCA to shut down the antegrade flow before initiating the catheterization to the aortic arch. C, The embolization of LSCA is performed with the vascular plug device, which is inserted through the inner lumen of the balloon catheter. $I D, 2.3 \mathrm{~mm} ; O D, 3.0 \mathrm{~mm}$.

Institutional Review Board, and individual oral and written informed consents were obtained from each patient.

Statistical analyses were conducted using SPSS software (SPSS Inc, Chicago, Ill). Categoric data were compared using the Fisher exact test. Continuous variables were expressed as mean \pm standard deviation and compared using $t$ test. Univariate and multivariate analyses were performed using the Cox proportional hazard models to evaluate the time-to-event effects of the covariables, including age, gender, CVD, IHD, low ejection fraction $(<40 \%), \mathrm{CKD}, \mathrm{COPD}$, malignancy, emergency, history of type $\mathrm{B}$ dissection, prior intervention on abdominal aortic aneurysm, prior median sternotomy, prior TEVAR repair, and use of BPLSCA. Clinically relevant variables with a $P$ value less than .05 in univariate analysis were included in multivariable regression analyses as candidates for backward stepwise variable selections. The survival and aortic death-free rates were estimated using the Kaplan-Meier method, and the differences between each group were determined by the log-rank analysis.

\section{RESULTS}

\section{Early Results (Entire Cohort)}

There was no 30-day mortality in both groups. The hospital mortality rate was $1.4 \%(1 / 71)$ for the BPLSCA group and $2.3 \%(2 / 86)$ for the control group, with no statistical difference between them $(P=1.0)$. In patients undergoing emergency d-TEVAR, hospital mortality was not detected in either of the groups.

The cause of hospital death in the BPLSAC group was pneumonia during prolonged hospitalization for 12 months. In the control group, 1 patient died of liver cirrhosis and 1 patient died of shower embolism.

Postoperative complications in the BPLSCA group included pneumonia in 2 patients $(2.8 \%)$, perioperative stroke in 0 patients $(0 \%)$, monoplegia without evidence of stroke on CT or magnetic resonance imaging in 1 patient $(1.7 \%)$, monoparesis without evidence of stroke on CT or magnetic resonance imaging in 1 patient $(1.7 \%)$, and intraoperative type A aortic dissection in 1 patient $(1.7 \%)$. In the control group, pneumonia occurred in 8 patients $(9.3 \%)$, perioperative stroke occurred in 7 patients $(8.1 \%)$, paraplegia occurred in 4 patients $(4.7 \%)$, monoplegia occurred in 1 patient $(1.2 \%)$, paraparesis occurred in 2 patients $(2.3 \%)$, and intraoperative type A aortic dissection occurred in 1 patient $(1.2 \%)$.

Perioperative stroke was significantly lower in the BPLSCA group than in the control group $(0 \%$ : $0 / 71$ vs 7.9\%: 7/86, $P=.014)$. Intraoperative type A aortic 


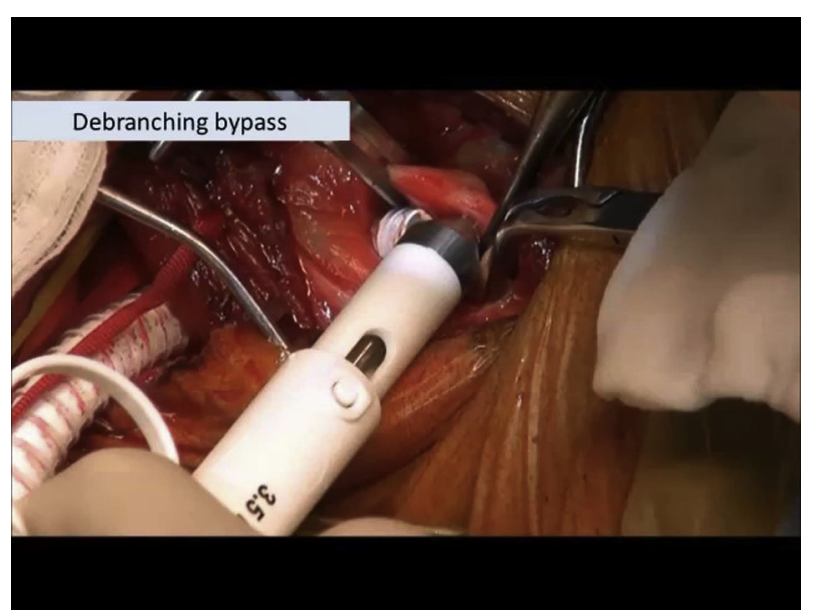

VIDEO 1. An 82-year-old man who had been diagnosed with aortic arch aneurysm, $55 \mathrm{~mm}$ in diameter, underwent d-TEVAR using BPLSCA. After initiating left carotid to left axillary artery bypass with an $8-\mathrm{mm}$ polytetrafluoroethylene (Gore-Tex; WL Gore \& Associates, Newark, Del) tube graft, a 9F sheath was inserted from the left axillary artery. BPLSCA was established before inserting the stent-graft system (Valiant; Medtronic, Inc, Minneapolis, Minn) inside the aortic arch. The exclusion of aneurysm was successfully completed with zone 1 landing. His postoperative course was uneventful without any symptom of stroke. He remains well without further aortic intervention for more than 6 months. Video available at: https://www.jtcvs.org/article/S0022-5223(18)32825-3/fulltext.

dissection in 2 patients occurred after d-TEVAR with zone 0 landing: in 1 patient because of the partial clamp for bypass in the control group, who was diagnosed by postoperative CT and treated medically, and in 1 patient because of complications during the chimney stent-graft technique in the BPLSCA group, which was then converted to emergency hemiarch replacement for unstable hemodynamics.

Any types of endoleaks were detected in 32 patients; type I in 7, type II in 3, and type II in 1 of the BPLSA group, and type I in 11, type in 9, and type II in 1 of the control group. The overall incidence of postoperative endoleak was found to be comparable between the BPLSCA and control groups $(11 / 71,16 \%$ vs $21 / 86,24 \%$; $P=.23)$.

\section{Clinical Characteristics and Outcome of Patients With Perioperative Stroke}

The characteristics and clinical manifestations of perioperative stroke are listed in Table 2. All patients were men with a mean age of $76 \pm 6.4$ years; 4 of 7 patients had histories of preoperative stroke, and no patient used BPLSCA during d-TEVAR.

The mean date of the diagnosis of symptomatic stroke was $2.4 \pm 3.9$ days postoperatively during hospitalization. The location of stroke indicated multiple foci in 4 patients, which was limited to the cerebellum in 2 and to the left cerebral hemisphere in 1 (Table 2).

\section{Late Results (Entire Cohort)}

The mean follow-up time was significantly shorter in the BPLSCA group ( $24 \pm 16$ months) than in the control group

TABLE 2. Clinical characteristics and outcome of patients with stroke

\begin{tabular}{|c|c|c|c|c|c|c|c|c|}
\hline & Age (y)/gender & History & $\begin{array}{l}\text { Supra-aortic } \\
\text { bypass }\end{array}$ & $\begin{array}{c}\text { Proximal } \\
\text { LZ }\end{array}$ & BPLSCA & $\begin{array}{l}\text { On set } \\
\text { (d) }\end{array}$ & $\begin{array}{c}\text { Location of } \\
\text { stroke }\end{array}$ & Symptom \\
\hline 1 & $76 / \mathrm{M}$ & $\begin{array}{l}\text { CVD } \\
\text { HD, COPD s/p } \\
\text { CABG, AAAR }\end{array}$ & $\begin{array}{l}\text { AAA graft-LAxA/ } \\
\text { CCA/RAxA }\end{array}$ & 0 & no & 0 & Multiple & $\begin{array}{l}\text { Persistent consciousness } \\
\text { disorder }\end{array}$ \\
\hline 2 & $74 / \mathrm{M}$ & CVD s/p TEVAR & $\begin{array}{c}\text { Aorta-bilateral } \\
\text { CCA/SCA }\end{array}$ & 0 & no & 10 & $\begin{array}{l}\text { Left cerebral } \\
\text { hemisphere }\end{array}$ & $\begin{array}{l}\text { Right upper-extremity } \\
\text { paraparesis }\end{array}$ \\
\hline 3 & $75 / \mathrm{M}$ & CVD & $\begin{array}{l}\text { Aorta-RAxA/ } \\
\text { LCCA/LAxA }\end{array}$ & 0 & no & 1 & $\begin{array}{l}\text { Right cerebral } \\
\text { hemisphere/ } \\
\text { bilateral } \\
\text { Cerebellar }\end{array}$ & Left-sided hemiparesis \\
\hline 4 & $68 / \mathrm{M}$ & HD s/p CABG & $\begin{array}{l}\text { RCCA-LCCA/ } \\
\text { LSCA }\end{array}$ & 1 & no & 0 & Multiple & $\begin{array}{l}\text { Persistent consciousness } \\
\text { disorder }\end{array}$ \\
\hline 5 & $73 / \mathrm{M}$ & $\begin{array}{l}\mathrm{HCC} \\
\mathrm{LC}\end{array}$ & $\begin{array}{l}\text { RAxA-LCCA/ } \\
\text { LAxA }\end{array}$ & 1 & no & 0 & Right cerebellar & Vision disturbance \\
\hline 6 & $78 / \mathrm{M}$ & CVD & $\begin{array}{l}\text { RAxA-LCCA/ } \\
\text { LAxA }\end{array}$ & 1 & no & 0 & Bilateral cerebellar & Vision disturbance \\
\hline 7 & 89/M & None & RAxA-LAxA & 2 & no & 6 & $\begin{array}{l}\text { Right cerebral } \\
\text { hemisphere/ } \\
\text { left cerebellar }\end{array}$ & $\begin{array}{l}\text { Left upper-extremity } \\
\text { paraparesis }\end{array}$ \\
\hline
\end{tabular}

$\overline{L Z}$, Landing zone; BPLSCA, balloon protection of proximal left subclavian artery; $M$, male; $C V D$, cerebrovascular disease; $H D$, hemodialysis; $C O P D$, chronic obstructive pulmonary disease; $s / p$, status post; $C A B G$, coronary artery bypass grafting; $A A A R$, abdominal aortic aneurysm repair; $A A A$, abdominal aortic aneurysm; $R / L A x A$, right/left axillary artery; $C C A$, common carotid artery; TEVAR, thoracic endovascular aortic repair; $S C A$, subclavian artery; $R / L C C A$, right/left common carotid artery; $R / L S C A$, right/left subclavian artery; $L C$, lung cancer; $H C C$, hepatocellular carcinoma. 

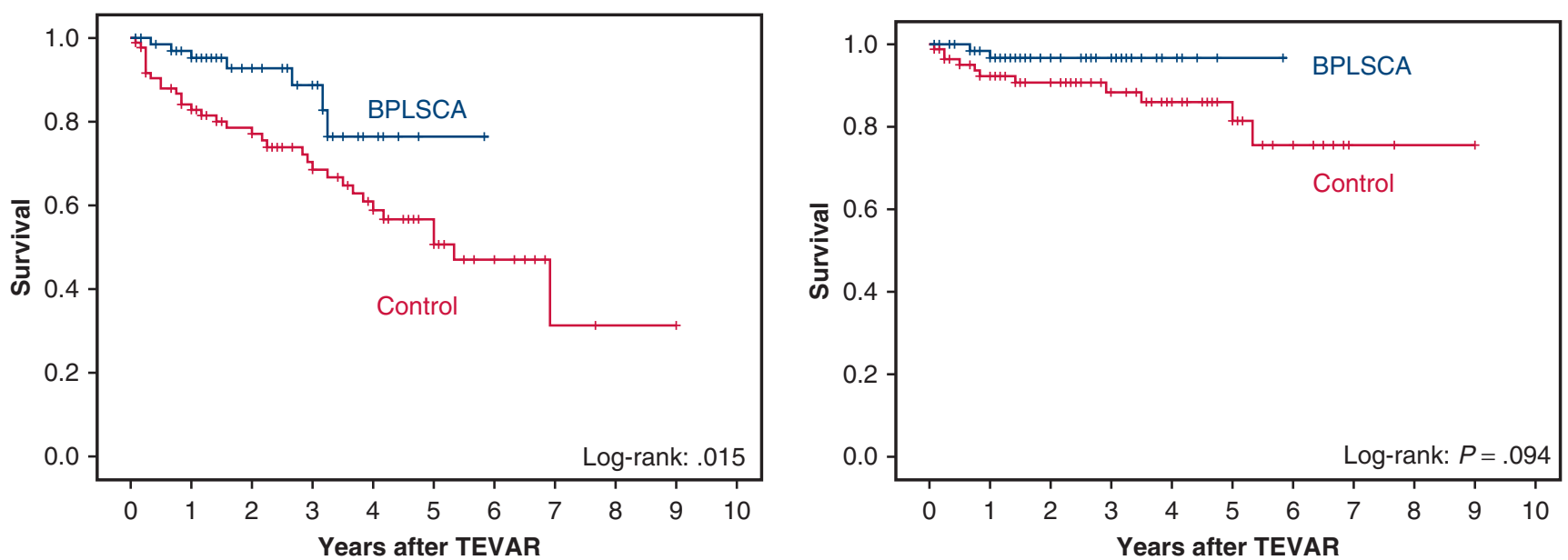

\begin{tabular}{|c|c|c|c|c|c|c|}
\hline & $\begin{array}{c}\text { time } \\
\text { (year) }\end{array}$ & $\begin{array}{c}\text { risk } \\
\text { number }\end{array}$ & survival & $\begin{array}{c}\text { standard } \\
\text { error }\end{array}$ & $\begin{array}{c}\text { lower } \\
95 \% \mathrm{Cl}\end{array}$ & $\begin{array}{c}\text { upper } \\
95 \% \mathrm{Cl}\end{array}$ \\
\hline \multirow{5}{*}{ BPLSCA } & 0.5 & 65 & 0.985 & 0.015 & 0.883 & 0.992 \\
\cline { 2 - 7 } & 1 & 56 & 0.952 & 0.027 & 0.859 & 0.984 \\
\cline { 2 - 7 } & 2 & 37 & 0.927 & 0.036 & 0.813 & 0.973 \\
\cline { 2 - 7 } & 3 & 14 & 0.828 & 0.075 & 0.616 & 0.929 \\
\cline { 2 - 7 } & 4 & 7 & 0.764 & 0.093 & 0.522 & 0.895 \\
\hline Control & 0.5 & 74 & 0.880 & 0.036 & 0.788 & 0.933 \\
\cline { 2 - 7 } & 1 & 64 & 0.828 & 0.042 & 0.727 & 0.895 \\
\cline { 2 - 7 } & 2 & 52 & 0.771 & 0.048 & 0.661 & 0.85 \\
\cline { 2 - 7 } & 3 & 38 & 0.685 & 0.056 & 0.562 & 0.781 \\
\cline { 2 - 7 } & 4 & 29 & 0.588 & 0.063 & 0.456 & 0.699 \\
\cline { 2 - 7 } & 5 & 13 & 0.471 & 0.074 & 0.364 & 0.633 \\
\hline
\end{tabular}

\begin{tabular}{|c|c|c|c|c|c|c|}
\hline & $\begin{array}{c}\text { time } \\
\text { (year) }\end{array}$ & $\begin{array}{c}\text { risk } \\
\text { number }\end{array}$ & survival & $\begin{array}{c}\text { standard } \\
\text { error }\end{array}$ & $\begin{array}{c}\text { lower } \\
95 \% \mathrm{Cl}\end{array}$ & $\begin{array}{c}\text { upper } \\
95 \% \mathrm{Cl}\end{array}$ \\
\hline BPLSCA & 0.5 & 65 & 0.984 & 0.015 & 0.894 & 0.998 \\
\cline { 2 - 7 } & 1 & 56 & 0.967 & 0.023 & 0.875 & 0.992 \\
\cline { 2 - 7 } & 2 & 37 & 0.967 & 0.023 & 0.875 & 0.992 \\
\cline { 2 - 7 } & 3 & 14 & 0.967 & 0.023 & 0.875 & 0.992 \\
\cline { 2 - 7 } & 4 & 7 & 0.967 & 0.023 & 0.875 & 0.992 \\
\hline Control & 0.5 & 74 & 0.951 & 0.024 & 0.874 & 0.981 \\
\cline { 2 - 7 } & 1 & 64 & 0.923 & 0.030 & 0.837 & 0.965 \\
\cline { 2 - 7 } & 2 & 52 & 0.885 & 0.040 & 0.778 & 0.942 \\
\cline { 2 - 7 } & 3 & 38 & 0.859 & 0.046 & 0.739 & 0.927 \\
\cline { 2 - 7 } & 4 & 29 & 0.859 & 0.046 & 0.739 & 0.927 \\
\cline { 2 - 7 } & 5 & 13 & 0.814 & 0.062 & 0.654 & 0.905 \\
\hline
\end{tabular}

FIGURE 2. Survival curves of entire cohort. A, Freedom from all causes of mortality at 2 and 4 years was significantly higher in the BPLSCA group compared with the control group (BPLSCA: $93 \% / 76 \%$ vs control: $77 \% / 59 \%, P=.015$ ). B, Freedom from aortic death at 2 and 4 years was similar in both groups (BPLSCA: $97 \% / 97 \%$ vs control: $91 \% / 86 \%, P=.094)$. BPLSCA, Balloon protection of proximal left subclavian artery; $C I$, confidence interval; TEVAR, thoracic endovascular aortic repair.

(35 \pm 26 months) $(P=.002)$. During the last follow-up period, the causes of late death in the BPLSCA group $(\mathrm{n}=5)$ included pneumonia in 3 patients $(4.3 \%)$, malignant tumor in 1 patient $(1.4 \%)$, and acute type $\mathrm{A}$ aortic dissection in 1 patient $(1.4 \%)$. In the control group, 30 late deaths occurred due to stroke in 5 patients $(6.0 \%)$, pneumonia in 5 patients $(6.0 \%)$, malignant tumor in 4 patients $(4.8 \%)$, gastrointestinal disorders in 4 patients $(4.8 \%)$, residual aortic aneurysm rupture in 4 patients $(4.8 \%)$, hemorrhagic cerebrovascular event in 2 patients (2.4\%), acute type A aortic dissection in 2 patients $(2.4 \%), \mathrm{CKD}$ in 1 patient $(1.2 \%)$, chronic heart failure in 1 patient $(1.2 \%)$, stent-graft infection in 1 patient $(1.2 \%)$, and unknown cause in 1 patient $(1.2 \%)$.

Freedom from all causes of mortality at 2 and 4 years was significantly higher in the BPLSCA group than in the control group $(93 \% / 76 \%$ vs $77 \% / 59 \%, P=.015)$ (Figure 2, A). Freedom from aortic death at 2 and 4 years was similar $(97 \% / 97 \%$ vs $91 \% / 86 \%, P=.094)$ (Figure 2, B).

\section{Analysis of Matched Cohorts by Propensity Score Matching}

No significant difference was noted in the baseline patient characteristics of the matched 51 pairs (Table 1). Perioperative stroke was significantly lower in the BPLSCA group $(0 \%$ : 0/51) than in the control group $(11.8 \%$ : 6/51) $(P=.012)$. PSM yielded similar results of better freedom from all causes of mortality in the BPLSCA group $(93 \% / 93 \%$ vs $81 \% / 63 \%, P=.017)$ and equivalent aortic death in both groups $(95 \% / 95 \%$ vs $92 \% / 88 \%, P=.30)$ (Figure 3, $A$ and $B$ ).

\section{Analysis of the Most Recent Cases Since 2012}

The mean follow-up time of the most recent cases since 2012 was $24 \pm 18$ months. Mean age was similar between the 2 groups ( $78 \pm 6.7$ years vs $79 \pm 7.9$ years, $P=.33$ ). Freedom from all causes of mortality at 2 and 4 years was significantly higher in the BPLSCA group than in the control group $(93 \% / 75 \%$ vs $67 \% / 54 \%, P=.009)$ 

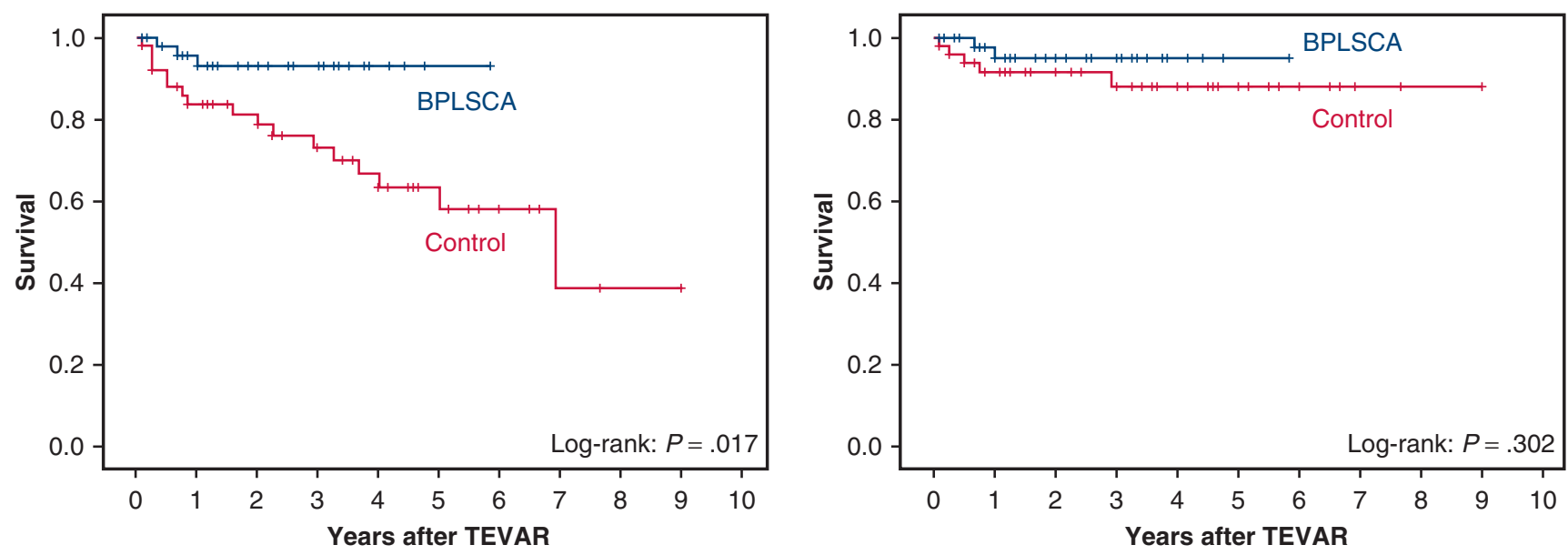

\begin{tabular}{|c|c|c|c|c|c|c|}
\hline & $\begin{array}{c}\text { time } \\
\text { (year) }\end{array}$ & $\begin{array}{c}\text { risk } \\
\text { number }\end{array}$ & survival & $\begin{array}{c}\text { standard } \\
\text { error }\end{array}$ & $\begin{array}{c}\text { lower } \\
95 \% \mathrm{Cl}\end{array}$ & $\begin{array}{c}\text { upper } \\
95 \% \mathrm{Cl}\end{array}$ \\
\hline BPLSCA & 0.5 & 46 & 0.978 & 0.022 & 0.856 & 0.997 \\
\cline { 2 - 7 } & 1 & 38 & 0.931 & 0.039 & 0.8 & 0.977 \\
\cline { 2 - 7 } & 2 & 24 & 0.931 & 0.039 & 0.8 & 0.977 \\
\cline { 2 - 7 } & 3 & 15 & 0.931 & 0.039 & 0.8 & 0.977 \\
\cline { 2 - 7 } & 4 & 6 & 0.931 & 0.039 & 0.8 & 0.977 \\
\hline Control & 0.5 & 44 & 0.877 & 0.047 & 0.746 & 0.943 \\
\cline { 2 - 7 } & 1 & 39 & 0.833 & 0.054 & 0.694 & 0.913 \\
\cline { 2 - 7 } & 2 & 32 & 0.783 & 0.061 & 0.632 & 0.877 \\
\cline { 2 - 7 } & 3 & 24 & 0.725 & 0.069 & 0.562 & 0.835 \\
\cline { 2 - 7 } & 4 & 19 & 0.624 & 0.08 & 0.446 & 0.759 \\
\cline { 2 - 7 } & 5 & 11 & 0.567 & 0.091 & 0.373 & 0.669 \\
\hline
\end{tabular}

\begin{tabular}{|c|c|c|c|c|c|c|}
\hline & $\begin{array}{c}\text { time } \\
\text { (year) }\end{array}$ & $\begin{array}{c}\text { risk } \\
\text { number }\end{array}$ & survival & $\begin{array}{c}\text { standard } \\
\text { error }\end{array}$ & $\begin{array}{c}\text { lower } \\
95 \% \mathrm{Cl}\end{array}$ & $\begin{array}{c}\text { upper } \\
95 \% \mathrm{Cl}\end{array}$ \\
\hline BPLSCA & 0.5 & 44 & 0.977 & 0.023 & 0.849 & 0.997 \\
\cline { 2 - 7 } & 1 & 38 & 0.952 & 0.034 & 0.819 & 0.988 \\
\cline { 2 - 7 } & 2 & 24 & 0.952 & 0.034 & 0.819 & 0.988 \\
\cline { 2 - 7 } & 3 & 15 & 0.952 & 0.034 & 0.819 & 0.988 \\
\cline { 2 - 7 } & 4 & 6 & 0.952 & 0.034 & 0.819 & 0.988 \\
\hline Control & 0.5 & 44 & 0.938 & 0.035 & 0.819 & 0.98 \\
\cline { 2 - 7 } & 1 & 39 & 0.914 & 0.041 & 0.787 & 0.967 \\
\cline { 2 - 7 } & 2 & 32 & 0.914 & 0.041 & 0.787 & 0.967 \\
\cline { 2 - 7 } & 3 & 24 & 0.878 & 0.052 & 0.723 & 0.949 \\
\cline { 2 - 7 } & 4 & 19 & 0.878 & 0.052 & 0.723 & 0.949 \\
\cline { 2 - 7 } & 5 & 11 & 0.878 & 0.052 & 0.723 & 0.949 \\
\hline
\end{tabular}

FIGURE 3. Survival curves of score-matched cohort. A, Freedom from all causes of mortality at 2 and 4 years was significantly higher in the BPLSCA group compared with the control group (BPLSCA: $93 \% / 93 \%$ vs control: $81 \% / 63 \%, P=.017$ ). B, Freedom from aortic death at 2 and 4 years was similar in both groups (BPLSCA: $95 \% / 95 \%$ vs control: $92 \% / 88 \%, P=.30$ ). BPLSCA, Balloon protection of proximal left subclavian artery; $C I$, confidence interval; TEVAR, thoracic endovascular aortic repair.

(Figure 4, A). Survival without stroke at 2 and 4 years was also significantly higher in the BPLSCA group than in the control group $(91 \% / 80 \%$ vs $62 \% / 50 \%, P=.001)$ (Figure 4, B).

When limited to the BPLSCA group, survival at 2 and 4 years without stroke was not different among 3 d-TEVAR techniques (zone 0: $89 \% / 89 \%$, zone 1: $95 \% / 86 \%$, zone 2 : $88 \% / 70 \%, P=.52)$.

\section{Risk Factors for All-Cause Mortality and Stroke During Follow-up}

With the use of Cox regression analysis, CVD (hazard ratio [HR], 1.7; $P=.001$ ) was found to be an independent positive predictor of postoperative mortality during the follow-up period. In contrast, the use of BPSCA (HR, 0.46; $P=.073$ ) demonstrated a trend toward a negative predictor of mortality (Table 3 ).

When limited to the incidence of stroke during the follow-up period, no variable was identified as a positive predictor. The use of BPSCA (HR, 0.13; $P=.051$ ) demonstrated a trend toward a negative predictor of stroke in univariate analysis (Table 4). Additional balloon protection for the other neck vessels was a negative predictor, but not significant.

\section{DISCUSSION}

The key issue of performing d-TEVAR for high-risk patients was not only to repair the aneurysm but also to maintain their preoperative daily living activities after the treatment. For such schemes, it is considerably important to prevent stroke due to embolic events through the neck vessels during d-TEVAR, which requires repeated catheterizations to the ascending aorta and aortic arch. ${ }^{11}$ Prior studies reported a relatively high incidence of stroke after d-TEVAR. ${ }^{3-5}$

Previous researchers indicated a higher mortality rate for patients with postoperative strokes, predictably. ${ }^{12,13}$ However, the solution for preventing perioperative stroke during d-TEVAR has not been established completely.

Melissano and colleagues ${ }^{8}$ reported that the stroke rate in patients in whom LSCA was patent at the time of endograft deployment was $4.5 \%$, but no stroke was encountered in 

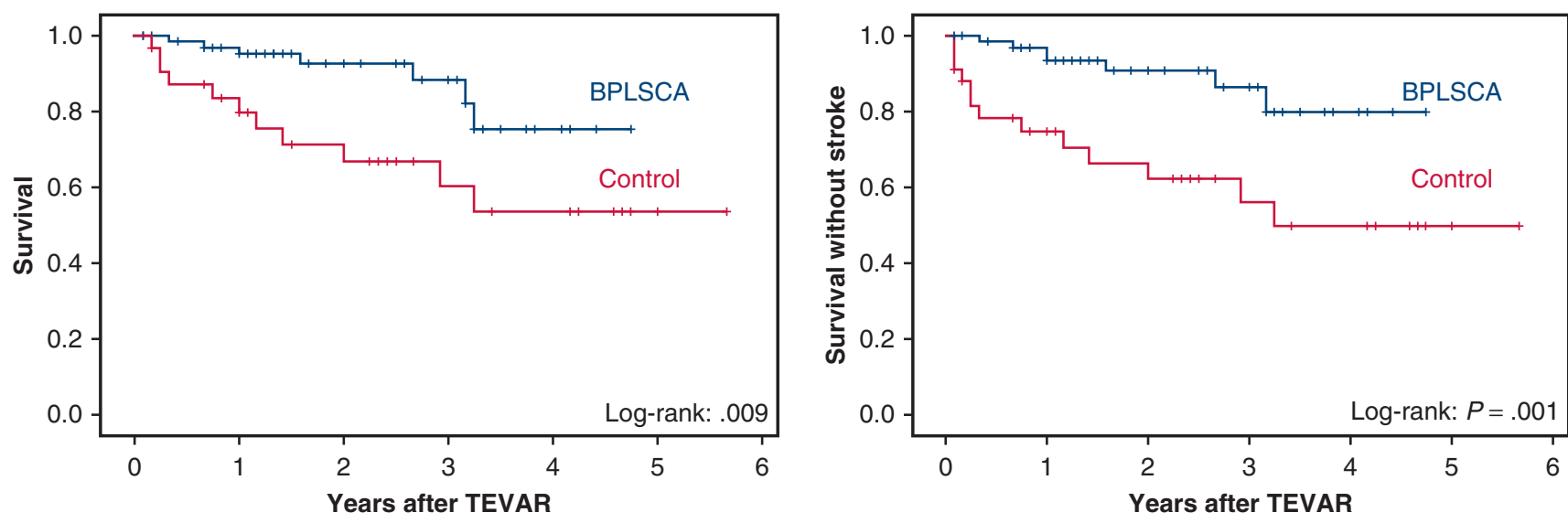

\begin{tabular}{|c|c|c|c|c|c|c|}
\hline & $\begin{array}{c}\text { time } \\
\text { (year) }\end{array}$ & $\begin{array}{c}\text { risk } \\
\text { number }\end{array}$ & survival & $\begin{array}{c}\text { standard } \\
\text { error }\end{array}$ & $\begin{array}{c}\text { lower } \\
95 \% \mathrm{Cl}\end{array}$ & $\begin{array}{c}\text { upper } \\
95 \% \mathrm{Cl}\end{array}$ \\
\hline BPLSCA & 0.5 & 65 & 0.985 & 0.015 & 0.896 & 0.998 \\
\cline { 2 - 7 } & 1 & 56 & 0.952 & 0.027 & 0.857 & 0.984 \\
\cline { 2 - 7 } & 2 & 37 & 0.926 & 0.037 & 0.81 & 0.972 \\
\cline { 2 - 7 } & 3 & 14 & 0.821 & 0.078 & 0.599 & 0.927 \\
\cline { 2 - 7 } & 4 & 7 & 0.752 & 0.098 & 0.499 & 0.89 \\
\hline Control & 0.5 & 28 & 0.872 & 0.06 & 0.694 & 0.95 \\
\cline { 2 - 7 } & 1 & 22 & 0.798 & 0.074 & 0.602 & 0.904 \\
\cline { 2 - 7 } & 2 & 16 & 0.669 & 0.092 & 0.455 & 0.815 \\
\cline { 2 - 7 } & 3 & 10 & 0.602 & 0.105 & 0.371 & 0.772 \\
\cline { 2 - 7 } & 4 & 9 & 0.535 & 0.112 & 0.299 & 0.7 \\
\hline
\end{tabular}

\begin{tabular}{|c|c|c|c|c|c|c|}
\hline & $\begin{array}{c}\text { time } \\
\text { (year) }\end{array}$ & $\begin{array}{c}\text { risk } \\
\text { number }\end{array}$ & survival & $\begin{array}{c}\text { standard } \\
\text { error }\end{array}$ & $\begin{array}{c}\text { lower } \\
95 \% \mathrm{Cl}\end{array}$ & $\begin{array}{c}\text { upper } \\
95 \% \mathrm{Cl}\end{array}$ \\
\hline BPLSCA & 0.5 & 65 & 0.985 & 0.015 & 0.896 & 0.998 \\
\cline { 2 - 7 } & 1 & 56 & 0.934 & 0.032 & 0.834 & 0.975 \\
\cline { 2 - 7 } & 2 & 36 & 0.908 & 0.04 & 0.789 & 0.962 \\
\cline { 2 - 7 } & 3 & 13 & 0.865 & 0.059 & 0.703 & 0.942 \\
\cline { 2 - 7 } & 4 & 6 & 0.799 & 0.083 & 0.574 & 0.913 \\
\hline Control & 0.5 & 25 & 0.783 & 0.073 & 0.596 & 0.89 \\
\cline { 2 - 7 } & 1 & 22 & 0.747 & 0.078 & 0.556 & 0.856 \\
\cline { 2 - 7 } & 2 & 16 & 0.622 & 0.092 & 0.417 & 0.773 \\
\cline { 2 - 7 } & 3 & 10 & 0.56 & 0.102 & 0.342 & 0.731 \\
\cline { 2 - 7 } & 4 & 9 & 0.498 & 0.108 & 0.277 & 0.684 \\
\hline
\end{tabular}

FIGURE 4. Survival curves of score-matched cohort of the most recent cases since 2012. A, Freedom from all causes of mortality at 2 and 4 years was significantly higher in the BPLSCA group compared with the control group (BPLSCA: $93 \% / 75 \%$ vs control: $67 \% / 54 \%, P=.009$ ). B, Survival without stroke at 2 and 4 years was also significantly higher in the BPLSCA group than in the control group (BPLSCA: $91 \% / 80 \%$ vs control: $62 \% / 50 \%, P=.001$ ). $B P L S C A$, Balloon protection of proximal left subclavian artery; $C I$, confidence interval; TEVAR, thoracic endovascular aortic repair.

patients in whom LSCA had been occluded beforehand. The authors also indicated that the main location of strokes was cerebellar, suggesting that the posterior cerebral embolism through the subclavian and vertebral arteries was the issue to be resolved.

Likewise, Yoshitake and colleagues ${ }^{7}$ described the efficacy of LSCA occlusion at the time of stent-graft deployment because the stroke location was mostly the posterior circulation, and, in more than half of the patients (4/7), cerebellar/cerebral infarction was noted in the lesions perfused only from the vertebral/basilar artery.

The rate of perioperative stroke was significantly lower in the BPLSCA group than in the control group $(P=.014)$. The location of their strokes indicated multiple focuses in 4 patients, limited to cerebellar in 2 patients, and left cerebellum in 1 patient. Of these patients, 6 had cerebellar infarction. Our result suggested that the use of BPLSCA may play an important role in reducing brain injury arising from the left vertebral artery.

It is technically important that the balloon is initially inflated to arrest the antegrade flow in LSCA before initiating catheterization to the aortic arch. In addition, aspiration of the blood between the stent-graft and the balloon through the balloon catheter was performed to remove the possible debris released from the aorta after the deployment of the endograft and before the embolization of LSCA.

In terms of embolization of LSCA, we routinely used coil devices previously. Since 2014, we converted the main device to the vascular plug. The rationale for using the plug for the closure of proximal LSCA has not been well established. However, the embolization with the plug has some advantages, such as shorter procedure time, no need for repeated catheterizations to LSCA, and a low probability of migration to the vertebral artery, compared with coil embolization. ${ }^{8,9,14,15}$

Since 2014, the patients assigned to BPLSCA showed no perioperative and late-phase stroke in this cohort. This strategy of using the plug during d-TEVAR may contribute to the reduction of stroke. Because we do not have sufficient evidence relating to the reduced incidence of stroke with using a plug instead of a coil, there is need for further follow-up to reveal the efficacy of this strategy using a plug.

The results of a meta-analysis in the BPLSCA group versus the control group for aortic arch aneurysms showed 
TABLE 3. Predictors of all causes of mortality (entire cohort)

\begin{tabular}{|c|c|c|c|c|}
\hline \multirow[b]{2}{*}{ Covariate } & \multicolumn{2}{|c|}{ Univariate } & \multicolumn{2}{|c|}{ Multivariate } \\
\hline & HR $(95 \%$ CI $)$ & $P$ value & HR $(95 \%$ CI) & $P$ value \\
\hline Age & $1.05(1.01-1.09)$ & .020 & $1.04(0.99-1.08)$ & .078 \\
\hline Female gender & $0.55(0.23-4.13)$ & .18 & & \\
\hline CVD & $1.67(1.22-2.29)$ & .001 & $2.36(1.24-4.48)$ & .009 \\
\hline IHD & $0.95(0.64-1.40)$ & .79 & & \\
\hline Low ejection fraction $(<40 \%)$ & $1.11(0.61-2.03)$ & .72 & & \\
\hline $\mathrm{CKD}(\mathrm{Cr}>1.5)$ & $1.18(0.74-1.89)$ & .49 & & \\
\hline COPD & $1.28(0.89-1.84)$ & .18 & & \\
\hline Malignancy & $1.51(1.02-2.24)$ & .041 & $1.64(0.73-3.66)$ & .23 \\
\hline Emergency & $1.17(0.73-1.86)$ & .52 & & \\
\hline History of type B dissection & $0.22(0.03-1.60)$ & .13 & & \\
\hline Prior intervention on AAA & $1.35(0.87-2.09)$ & .19 & & \\
\hline Prior median sternotomy & $1.09(0.64-1.84)$ & .76 & & \\
\hline Prior TEVAR repair & $1.10(0.60-2.00)$ & .77 & & \\
\hline Use of BPLSCA & $0.61(0.40-0.92)$ & .020 & $0.46(0.19-1.07)$ & .073 \\
\hline
\end{tabular}

that the BPLSCA group significantly improved the operative mortality, whereas it was not associated with aortic death.

Prospective randomized control trials seem to be most appropriate for comparing the outcomes of both the surgical strategies; however, they are realistically difficult. To compensate for this issue, we performed PSM to equalize

TABLE 4. Predictors of stroke during follow-up periods (entire cohort)

\begin{tabular}{llc}
\hline \multirow{2}{*}{\multicolumn{1}{c}{ Covariate }} & \multicolumn{2}{c}{ Univariate } \\
\cline { 2 - 3 } Age & HR $(\mathbf{9 5} \% \mathbf{C I})$ & $\boldsymbol{P}$ value \\
\hline Female gender & $1.03(0.95-1.11)$ & .45 \\
CVD & $0.58(0.21-1.62)$ & .29 \\
IHD & $1.50(0.83-2.71)$ & .18 \\
\hline Low ejection fraction $(<40 \%)$ & $1.17(0.60-2.28)$ & .64 \\
CKD $($ Cr $>1.5)$ & $4.98(0.04-651)$ & .52 \\
COPD & $0.21(0.03-16.8)$ & .48 \\
Malignancy & $1.33(0.68-2.58)$ & .40 \\
\hline Emergency & $0.87(0.31-2.44)$ & .79 \\
History of type B dissection & $0.94(0.34-2.64)$ & .91 \\
\hline Prior intervention on AAA & $0.04(0.00-132)$ & .44 \\
Prior median sternotomy & $1.04(0.37-2.92)$ & .94 \\
\hline Prior TEVAR repair & $1.06(0.38-2.98)$ & .91 \\
\hline Use of BPLSCA & $0.21(0.00-61.7)$ & .59 \\
\hline
\end{tabular}

$H R$, Hazard ratio; $C I$, confidence interval; $C V D$, cerebrovascular disease; $I H D$, ischemic heart disease; $C K D$, chronic kidney disease; $C r$, creatinine; $C O P D$, chronic obstructive pulmonary disease; $A A A$, abdominal aortic aneurysm; $T E V A R$, thoracic endovascular aortic repair; $B P L S C A$, balloon protection of proximal left subclavian artery. the patient selection bias. This analysis revealed similar results of better freedom from all causes of mortality in the BPLSCA group and equivalent aortic death compared with that in the original cohort. Furthermore, perioperative stroke was also significantly lower in the BPLSCA group than in the control group in the matched cohort. This result suggested that BPLSCA may contribute to the reduction of perioperative stroke and the improvement of mortality.

According to the landing zone, 3 different bypass surgeries were performed and the source of embolic stroke also could be different. However, the survival without stroke was not different among 3 debranching techniques. This could be because the aneurysm always involved or was located near the LSCA, and embolic stroke was expected most frequently via the LSCA and left vertebral artery. Therefore, matching for the proximal landing zone was not indicated.

Multiple regression analysis highlighted 2 other clinically relevant aspects that confirmed our observations. First, d-TEVAR for patients with CVD revealed a higher rate of mortality due to all causes, but the use of BPLSCA demonstrated a trend toward a negative predictor of mortality. This outcome may reflect that atherosclerotic changes are located at the aortic arch and neck vessels, which are well established as substantial risk factors for cerebral infarction. ${ }^{16}$ We generally select d-TEVAR for patients with CVD for their frail systemic condition, which may result in poor prognosis consequently. In such a situation, BPLSCA may have protective effects against embolic events, especially to the left vertebral artery.

Second, when limited to the incidence of stroke, no variable was identified as a positive predictor, but the use 
of BPLSCA demonstrated a trend toward a negative predictor of stroke. This outcome enhanced the effect of BPLSCA on reducing stroke events. Fundamentally, the shaggy aorta may be well established as a substantial risk factor for stroke. ${ }^{6,17}$ However, the relationship between shaggy aorta and stroke was not evaluated because of the difficulty in quantitatively defining shaggy aorta in this study.

\section{Study Limitations}

Our study limitations are as follows: This was a single-center, observational, retrospective study on a specific cohort of a small sample size. Further investigations and follow-ups are required to support the efficacy of BPLSCA for treating aortic arch pathologies during d-TEVAR. The reintervention rate was not evaluated in this study, because the indication of reintervention in the elderly is often affected by other conditions, such as frailty or dementia. Finally, BPLSCA was applied in the recent series of patients after 2012 based on the higher percentage of stroke complicated in the early phase of the program. Therefore, the results in this study might be influenced by the improvement of patient management and devices.

\section{CONCLUSIONS}

d-TEVAR using BPLSCA revealed more appropriate early and late outcomes. Evaluation using PSM enhanced the efficacy of BPLSCA. The comprehensive strategy to prevent stroke during d-TEVAR, including BPLSCA, contributed to the marked reduction in the chances of stroke and mortality.

\section{Conflict of Interest Statement}

Authors have nothing to disclose with regard to commercial support.

\section{References}

1. Patel HJ, Shillingford MS, Williams DM, Upchurch GR Jr, Dasika NL, Prager RL, et al. Survival benefit of endovascular descending thoracic aortic repair for the high risk patient. Ann Thorac Surg. 2007;83:1628-34.

2. Ferrero E, Ferri M, Viazzo A, Robaldo A, Zingarelli E, Sansone F, et al. Is total debranching a safe procedure for extensive aortic-arch disease? A single experience of 27 cases. Eur J Cardiothorac Surg. 2012;41:177-82.
3. Murashita T, Matsuda H, Domae K, Iba Y, Tanaka H, Sasaki H, et al. Less invasive surgical treatment for aortic arch aneurysms in high-risk patients: a comparative study of hybrid thoracic endovascular aortic repair and conventional total arch replacement. J Thorac Cardiovasc Surg. 2012;143:1007-13.

4. Ullery BW, McGarvey M, Cheung AT, Fairman RM, Jackson BM, Woo EY, et al. Vascular distribution of stroke and its relationship to perioperative mortality and neurologic outcome after thoracic endovascular aortic repair. J Vasc Surg. 2012; 56:1510-7.

5. Bavaria J, Vallabhajosyula P, Moeller P, Szeto W, Desai N, Pochettino A. Hybrid approaches in the treatment of aortic arch aneurysms: postoperative and midterm outcomes. J Thorac Cardiovasc Surg. 2013;145:85-90.

6. Virmani R, Burke AP, Kolodgie FD, Farb A. Pathology of the thin-cap fibroatheroma: a type of vulnerable plaque. J Interv Cardiol. 2003;16:267-72.

7. Yoshitake A, Hachiya T, Okamoto K, Kitahara H, Kawaguchi S, Nakatsuka S, et al. Postoperative stroke after debranching with thoracic endovascular aortic repair. Ann Vasc Surg. 2016;36:132-8.

8. Melissano G, Tshomba Y, Bertoglio L, Rinaldi E, Chiesa R. Analysis of stroke after TEVAR involving the aortic arch. Eur J Vasc Endovasc Surg. 2012;43: 269-75.

9. Inoue Y, Matsuda H, Fukuda T, Sanda Y, Morita Y, Oda T, et al. Utility of chimney stentgraft technique for patients with short zone 1. Ann Vasc Dis. 2015;8:302-6.

10. Kato M, Kagaya H, Kubo Y, Banno H, Ohkubo N. Real chimney technique for total debranching of supra-aortic trunks. J Vasc Surg. 2015;61:542-5.

11. Rehders TC, Petzsch M, Ince H, Kische S, Korber T, Koschyk DH, et al Intentional occlusion of the left subclavian artery during stent-graft implantation in the thoracic aorta: risk and relevance. J Endovasc Ther. 2004;11 659-66.

12. Gutsche JT, Cheung AT, McGarvey ML, Moser WG, Szeto W, Carpenter JP, et al Risk factors for perioperative stroke after thoracic endovascular aortic repair. Ann Thorac Surg. 2007;84:1195-200.

13. Mariscalco G, Piffaretti G, Tozzi M, Bacuzzi A, Carrafiello G, Sala A, et al Predictive factors for cerebrovascular accidents after thoracic endovascular aortic repair. Ann Thorac Surg. 2009;88:1877-81.

14. Meyer C, Probst C, Strunk H, Schiller W, Wilhelm K. Second-generation Amplatzer Vascular Plug (AVP) for the treatment of subsequent subclavian backflow type II endoleak after TEVAR. Cardiovasc Intervent Radiol. 2009; 32:1264-7.

15. Iida $\mathrm{Y}$, Ito $\mathrm{T}$, Hayashi $\mathrm{S}$, Takahashi $\mathrm{T}$, Misumi $\mathrm{T}$, Hachiya $\mathrm{T}$, et al Repair of acute type B aortic dissection complicated by aortic rupture with debranching thoracic endovascular aortic repair and left subclavian artery occlusion using Amplatzer Vascular Plug II. Ann Vasc Dis. 2015; $8: 252-4$.

16. Kanaoka Y, Ohki T, Maeda K, Baba T, Fujita T. Multivariate analysis of risk factors of cerebral infarction in 439 patients undergoing thoracic endovascular aneurysm repair. Medicine (Baltimore). 2016;95:e3335.

17. Seike Y, Minatoya K, Sasaki H, Tanaka H, Itonaga T, Oda T, et al. Preoperative assessment of high-risk aortic plaque by magnetization-prepared rapid acquisition with gradient-echo imaging in a patient with total arch replacement. Ann Vasc Dis. 2015;8:337-9.

Key Words: aortic arch aneurysm, balloon protection, debranching thoracic endovascular aortic repair, left subclavian artery, stroke 


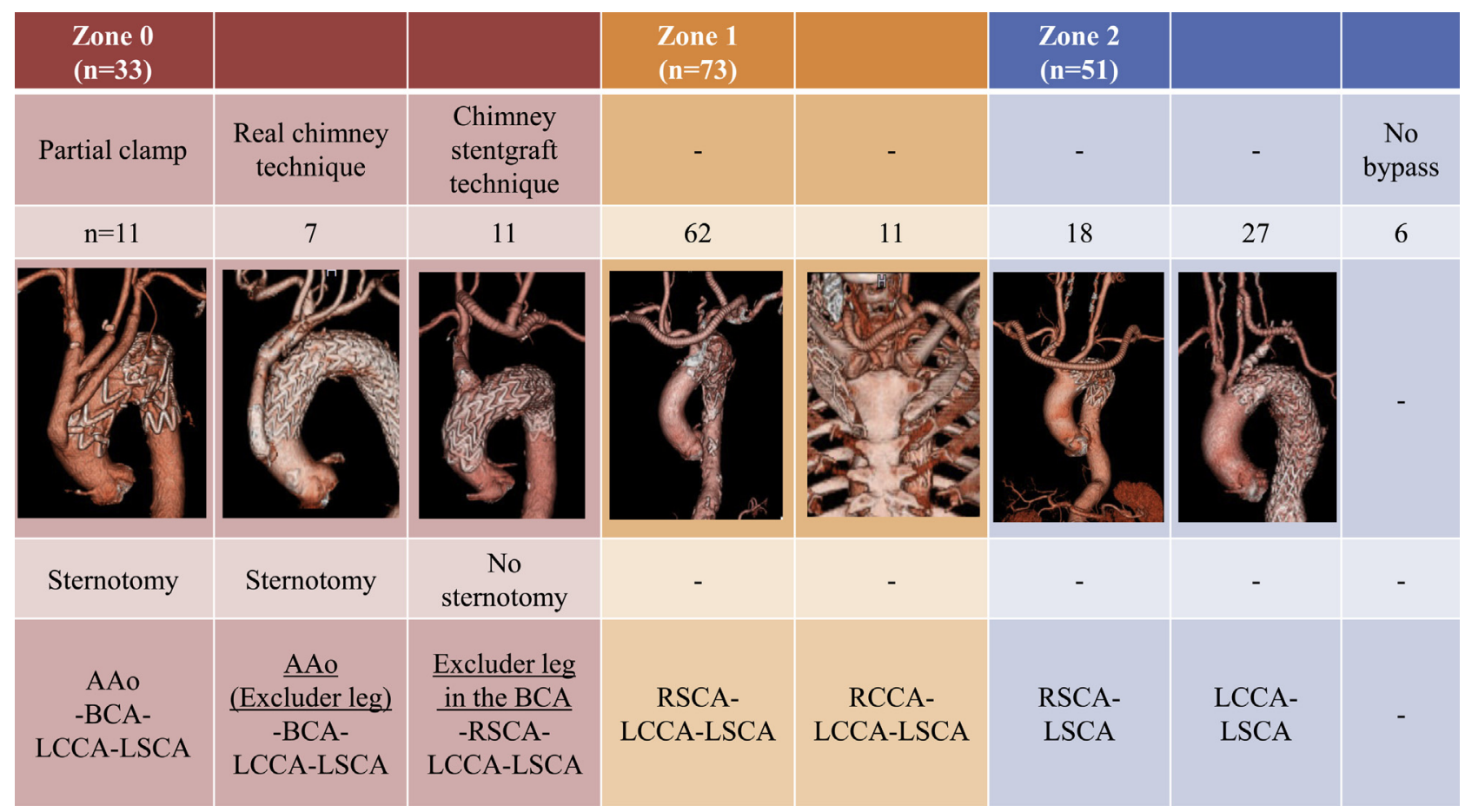

FIGURE E1. The different technical approaches for the debranching TEVAR used in this study are listed. $A A O$, Ascending aorta; $B C A$, brachiocephalic artery; $R / L C C A$, right/ left common carotid artery; $R / L S C A$, right/ left subclavian artery. 